ar a pair of Bluebirds whose young were ready to leave. On four occasions the uebirds renested in the new house. On two occasions they used the original house. his is all we tried.

By keeping notes on each Bluebird house and by banding adult nesting birds, an teresting piece of information was collected on Tree Swallows. On three occasions found more than one female Tree Swallow incubating a clutch of eggs or feeding ung. At any one time there was only one female in the house but we caught other males either sitting on the eggs or feeding the young.

\title{
Hatched Egg-Shells Covering COMMON TERN EGGS
}

\author{
by DAVID R. M. HATCH*
}

While conducting a study on Little eorge Island $\left(52^{\circ} 51^{\prime}-97^{\circ} 47^{\prime}\right)$, Lake innipeg, between July 1 and July 10 , 71. I made an unusual observation in ommon Terns regarding hatched eggells.

In each of seven nests, one egg in the utch of two or three was covered by e large end of an egg-shell from a hated egg. In each case, the additonal ell was firmly stuck over the large end the unhatched egg. I removed the exa egg-shell from six eggs. In two of ese six cases, the big end of the unhateed egg was already pipped. Chicks itched within 24 hours from four of ese six eggs. The two remaining eggs ch contained fully developed dead pung. All four young from the eggs hich hatched were accepted by their rents. In the seventh egg from which I d not remove the additional shell, the iick failed to hatch.

$\mathrm{N}$. Tinbergen refers to the large end the hatched egg as the "small 'lid' at e obtuse end which comes off during itching."'s In dealing with the Blackaded Gull, Tinbergen suggested that ie of the reasons for egg-shell removal the possibility that this "lid" might end to slip over an unhatched egg, us trapping the chick in a double ell." This may have occurred in the ise of the Little George observations.

Adults that I observed generally

lanitoba Muscum of Man and Vature

190 Rupert Avenue

Winnipeg. Manıtoba R3B ON2 carried the hatched portions of eggs from their territory and usually out of the colony. This behaviour differs somewhat from that described by R. S. Palmer who wrote that "adults may fly up with a shell, then drop it while they are still over their own nesting territory.". He did not mention eggshells slipping over the ends of unhatched eggs.

There is the possibility that these "lids" were actually placed over the unhatched eggs. In the Honey Buzzard, the two halves of a hatched egg-shell are placed one inside the other before they are removed from the nest.' My observations may represent a similar tendency in Common Terns, or they may merely show a failure of some aclults to remove egg-shells following hatching with the resultant accidental slippage of the "lids" over unhatched eggs.

I would like to thank Dr. Roger $M$. Evans, Dr. Kees Vermeer, and Dr. Robert W. Nero for their assistance in reviewing the manuscript. My work was undertaken while employed by the Canadian Wildlife Service.

'ARMSTRONG, E. A. In: A. L. Thomson, ed 1964. A new dictionary of birds. McGraw-Hill Book Company, New York

PALMER, R. S. 1941. A belavior study of the Common Tern. Boston Socicty of Natural History, 42: 1-119.

TTINBERGEN, N., G. J. BROEKHUYSEN, F FEEKES, J. C. W. HOUGHTON, H. KRUUK, and E. SZULE. 1962. Egg-shell remesvel by the Black-headed Gull (Larus ridibundus L.): a behaviour component of camouflage. Behaviour. 19: 74-118. 